\title{
Changes in woody plant composition of three vegetation types exposed to a similar fire regime for over 46 years
}

\author{
Grace Nangendo $^{\mathrm{a}, *}$, Alfred Stein ${ }^{\mathrm{a}}$, Hans ter Steege ${ }^{\mathrm{b}}$, Frans Bongers $^{\mathrm{c}}$ \\ ${ }^{a}$ International Institute for Geo-Information Science and Earth Observation (ITC), \\ Natural Resources, P.O. Box 6, Hengelosestraat 99, 7500 AA Enschede, Overijssel, The Netherlands \\ ${ }^{\mathrm{b}}$ National Herbarium Netherlands, Utrecht University Branch, Heidelberglaan 2, 3584 CS Utrecht, The Netherlands \\ ${ }^{\mathrm{c}}$ Forest Ecology and Forest Management Group, Center for Ecosystem Studies, \\ Wageningen University, P.O. Box 47, 6700 AA Wageningen, The Netherlands
}

Received 8 February 2005; received in revised form 23 May 2005; accepted 4 July 2005

\begin{abstract}
The effect of regular burning of woodland vegetation in Africa over an extended period (46 years) was studied in the Murchison Falls National Park, Uganda. Areas identified as having different vegetation types in 1958 were revisited to analyze vegetation changes and to test the prediction that convergence would occur as a result of the regular fire. In each of the three vegetation cover types, a transect was analysed.

Results show that the vegetation cover types have changed and there is evidence of vegetation convergence. A detrended correspondence analysis (DCA) and a Morisita similarity index analysis showed a good separation between the 1958 and 2004 transects for each of the vegetation cover types. The DCA also showed that the three 2004 transects were compositionally closer to each other than the 1958 transects. The 2004 transects had also shifted away from the 1958 transects. Whereas in 1958 compositional similarity was highest between the Terminalia glaucescens conversion transect (T2) and the wooded grassland conversion transect (T3) (0.86), in 2004 it was most similar between the transects closest to Wairingo river (T1 and T2, correlation coefficient of 0.80 ). T1 was referred to as the Terminalia woodland transect. Comparing the 2004 transects to the 1958 transects, a low compositional similarity was observed. The highest was between T3-1958 and T3-2004 (0.62). Additionally, fewer indicator species (species specific for one transect) were identified in 2004 than in 1958 and, the transects shared more species in 2004 than in 1958. All the big trees $(\mathrm{DBH} \geq 30 \mathrm{~cm})$ that existed along T1 in 1958 died off. Clustering of individual woody plants, a protective mechanism used by plants in presence of fire, was identified in each of the plots analysed.

To counterbalance the unifying effect of fire for the vegetation in the area and to maintain diverse vegetation, a variety of fire management regimes are needed.
\end{abstract}

(C) 2005 Elsevier B.V. All rights reserved.

Keywords: Fire; Vegetation changes; Woody plants; Uganda

\footnotetext{
* Corresponding author. Tel.: +31 53 4874444; fax: +31 534874388 .

E-mail address: Nangendo@itc.nl (G. Nangendo).
} 


\section{Introduction}

The effect of fire and elephant disturbance to woodland vegetation in Africa is well documented (Dublin et al., 1990; Eckhardt et al., 2000; Laws, 1970; Leuthold, 1977; Spence and Angus, 1971). With high numbers of elephants, their intensive grazing, browsing and rubbing on the boles of woody vegetation work together to reduce or deter growth of these plants (Ben-Shahar, 1993; Laws, 1970; Sheil and Salim, 2004; Smart et al., 1985; Van Wijngaarden, 1985). Fires reduce or prevent settlement of forest species in the savannas (Favier et al., 2004) while promoting the survival of the fire resistant species (Smart et al., 1985). Fire and elephants being jointly active as disturbance agents have an intertwined effect: elephants open up thickets which in turn allow encroachment of more combustible grass thus creating conditions for easier spread of fire. Debarking of trees by elephants also makes the trees more susceptible to fire destruction (Buechner and Dawkins, 1961; Tafangenyasha, 2001; Yeaton, 1988).

Many studies were carried out during a period in which both elephants and fire were active disturbance agents and most of these emphasized the negative effect of high densities of elephants on large trees (Barnes, 1983; Laws, 1970; Lewis, 1986). This led to enforcing management policies, such as culling, which, coupled with poaching, almost led to extermination of elephants (Western and Maitumo, 2004) from many protected areas. After the reduction of elephants, little attention was paid to the effect of fire on the vegetation despite the continued debate on fire use as a management option in conservation areas (Trollope, 1993; van Wilgen et al., 1998). Monitoring studies on vegetation changes after elephant elimination were also rare and most were carried out soon after the elephants were reduced (Smart et al., 1985). In view of the ongoing use of fire as a management tool in conservation areas, a better understanding of the effects of fire on woody vegetation is needed (Sheil and Salim, 2004; Wheater, 1971), especially with respect to the determination of acceptable limits of change (Eckhardt et al., 2000).

The season of fire, fire frequency and fire intensity are major factors that influence tree survival (Gautier and Spichiger, 2004). The effect of these factors is, however, intertwined. The season of fire affects the species' reproductive ability and influences fire intensity, which in turn determines the species that survive after a fire. Fire intensity also increases in presence of a high fuel load (Leuthold, 1996; McShane, 1987; Sabiti and Wein, 1988; Salvatori et al., 2001), which would be the case after the elimination of the elephants (Smart et al., 1985) and other large herbivores, e.g. the buffalos, hartebeest, Uganda kob and waterbuck. The frequency of fire relative to the life cycle of a plant and subsequent opportunities for seed formation will have great influence in determining the species that exist in an area (Chandler et al., 1983). Regeneration patterns are, however, determined by interactions between the disturbance regime and the species' biology (Kennard et al., 2002; Pickett and White, 1985; Sagar et al., 2003).

The spatial arrangement of woody plants in an area is in part determined by the species present, the life history survival strategy of the species (Leps et al., 2001) and the disturbance history of the stand (Wells and Getis, 1999). When the fire regime is an important disturbance factor, it controls the size of clusters of woody plants (Favier et al., 2004). Clustering, on the other hand, reduces fire impact on the woody plants (Witkowski and Garner, 2000). Hence, analysis of woody plants patterns would further our understanding of the plants' survival mechanisms in the prevailing conditions.

In the present study, we evaluate changes in woody plant composition that has occurred over the last 46 years in three areas in Murchison Falls National Park. These areas were studied in 1958 and were then identified as belonging to different vegetation types. Before 1958 the area was always burnt once a year during the hottest season (December-February) (Buechner and Dawkins, 1961). Despite recommendations made on fire regime variation for the different vegetation types (Spence and Angus, 1971), a regular (annual) fire regime has been used for the last 46 years (Lock, 1977; Smart et al., 1985; Uganda Wildlife Authority, 2001). This late season burning was confirmed by field staff and also observed during data collection (January-February 2004). In 1958 and before, the area had high numbers of elephants and other large herbivores. These animals were hunted almost to extinction in the 1960s and early 1970s. Whereas the debarking of trees by the elephants makes them more vulnerable to fire, the grazing by high 
numbers of herbivores reduces the fuel load and thus reduces the fire intensity (McGuffog et al., 2001; van Langevelde et al., 2003). The elimination of herbivores, including elephants, must have, therefore, resulted in increase of the fuel load, which allowed for more intense fires. Other factors, e.g. climate have not significantly changed in the last 46 years. The questions addressed in this study therefore are: how did the vegetation change in the last 46 years? Is the change a convergent one? And, which could be the role of the fire regime in these changes? Are plants spatially clustered along each transect?

\section{Materials and methods}

\subsection{Study area}

The study area is located in Murchison Falls National Park, northwestern Uganda (Fig. 1). The Park has an average elevation of $800 \mathrm{~m}$. The rainfall varies between 1000 and $1250 \mathrm{~mm}$ annually and it falls mainly during the "long rains" from April to June and the "short rains" in September and October. Wairingo area, the location of our study site, receives an average of $1270 \mathrm{~mm}$ of rain annually and has an annual average of 117 rain days (Laws et al., 1975). The main dry season is from mid-December to mid-February.
The park has a long history of disturbance, especially caused by elephants and fire use (Buechner and Dawkins, 1961; Hatton and Smart, 1984; Laws, 1970). Several short-term studies carried out on the effect of the disturbances on vegetation in the 1960s and early 1970s showed that with elimination of fire and/or elephants, there was higher vegetation regeneration (Lock, 1977; Spence and Angus, 1971). At that time inference to the previous vegetation states was based on circumstantial evidence, e.g. vegetation relics. In 1958, Buechner and Dawkins had carried out a study in which they described the vegetation of Murchison Falls National Park. Part of the data was collected from the area close to Waringo ranger post. Here, the authors identified three vegetation types, i.e. a Terminalia woodland, a Terminalia glaucescens conversion and a wooded grassland conversion. The naming of the vegetation types could have, probably, been prompted by what the authors observed in the field because they record that the woody plants within the area were being destroyed by a combined influence of the elephants (Loxodonta africana) and fire thus converting the woodlands into grassland areas. Within each of the vegetation types, they collected data along a single transect. These same transects were revisited in the current study.

Although the stakeholders that carry out the burning have changed over time, the time and frequency of

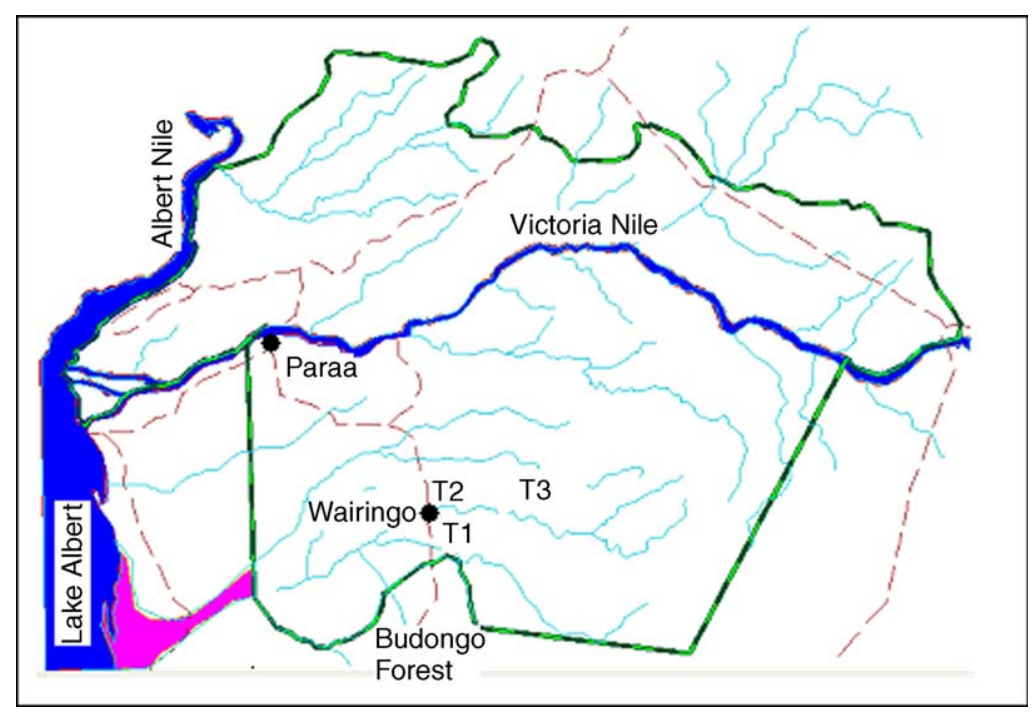

Fig. 1. The map of Murchison Falls National Park showing the data collection sites (T1, T2 and T3) close to Wairingo river. 
burning has not changed. At the time of Buechner and Dawkins' research, the local people set fires between December and February until the entire area was burnt (Buechner and Dawkins, 1961). This was done to provide grassy vegetation for wild as well as domestic ungulates and to ease the hunting activity by providing better visibility. Currently, the park authorities set the fire but local people also set fires at the fringes of the conservation area, which occasionally spread into the park. Each part is burnt once every year during the hottest season (December-February). The park authority burns to provide fresh grass for the herbivores as well as to counteract the local people's burning, which aims at attracting animals to outside of the conservation area (Uganda Wildlife Authority, 2001).

\subsection{Data collection}

To be able to describe the vegetation changes in the last 46 years, we collected the same type of data and used the same methods as had been done earlier by Buechner and Dawkins (1961). They collected vegetation data along transects in areas of the different vegetation types. Rectangular plots of $20 \mathrm{~m} \times 50 \mathrm{~m}$ were randomly established at intervals ranging from 200 to $300 \mathrm{~m}$ along transects running in the west-east direction. Buechner and Dawkins established three transects and data for this study was collected along these same transects. The first plot of transect one (T1) located $500 \mathrm{~m}$ south of the survey Marker (elevation $764 \mathrm{~m}$ ) at Wairingo ranger post, was at UTM coordinate 357564, 230036, the first plot of transect two (T2) located $1000 \mathrm{~m}$ north of Wairingo ranger post, was at UTM coordinate 357213, 232915 and the first plot of transect three (T3) located $10 \mathrm{~km}$ northeast of the Wairingo ranger post, was at UTM coordinate 364168,239056 . The coordinates for the rest of the plots on each transect are available at the UWA library and with the corresponding author. Whereas transect one was located south of Wairingo river, transects two and three were located north of Wairingo river. Along T1, T2 and T3, we established 10, 5 and 5 plots, respectively, the same number of plots that was established by Buechner and Dawkins in 1958.

For each plot, we recorded plot coordinates and for all woody plants with diameter at breast height (DBH) we recorded the DBH and species name, for woody plants of $\mathrm{DBH}<2 \mathrm{~cm}$ and height $\geq 50 \mathrm{~cm}$, the species name and abundance of individuals was recorded. Also, presence/absence of bark destruction (old or fresh scars) for each woody plant with $\mathrm{DBH} \geq 2 \mathrm{~cm}$ was recorded. For one randomly selected plot on each of the transects T1, T2 and T3, coordinates were recorded for each woody individual $(\mathrm{DBH} \geq 2 \mathrm{~cm}$ ) to allow for a more detailed analysis of woody plant distribution. These three plots are denoted $\mathrm{T} 1_{\mathrm{p}}, \mathrm{T} 2_{\mathrm{p}}$, and $\mathrm{T} 3_{\mathrm{p}}$, respectively.

Species identification was based on Eggeling and Dale (1952) and Hamilton (1991). Samples of the species that could not be clearly identified in the field by the botanist on the team were sent to the Uganda National Herbarium where they were identified. The 1958 species list was also checked for changes in species nomenclature.

\subsection{Data analysis}

The data set of 2004 was separated into three groups: trees $\quad(\mathrm{DBH} \geq 10 \mathrm{~cm}), \quad$ saplings $\quad(\geq 2 \mathrm{~cm} \mathrm{DBH}<$ $10 \mathrm{~cm}$ ), and seedlings (DBH $<2 \mathrm{~cm}$ and height $\geq$ $50 \mathrm{~cm}$ ). Comparison of species abundance between the transects was carried out based on the three groups.

\subsubsection{8-2004 vegetation changes}

To identify changes that had occurred between 1958 and 2004 along the transects, several methods were used. First we calculated the similarity coefficient $(r)$ among the transects using the Sørensen similarity measure (Janson and Vegelius, 1981). Comparisons were made among the 1958 transects, among the 2004 transects and between the 1958 and 2004 transects.

Comparison between transects in terms of species composition was made using species relative abundance values for each transect in the respective year (1958 and 2004). Detrended correspondence analysis (DCA) was used to explore these differences. The proximity of transects to each other along the resulting DCA gradient space reveals similarity in species composition. Relative abundance values were calculated as

relative abundance of a species

$$
=\frac{\text { abundance of a species }}{\text { abundance of all species }} \times 100
$$


To check for compositional similarity at plot level, the Modified Morisita similarity index, which is less sensitive to the abundance of the most abundant species than the unmodified one, was used (Wolda, 1983).

\subsection{Species composition}

To further test for differences in species composition between the transects we used the multipleresponse permutation procedure (MRPP) and the indicator species analysis of PC-ORD (McCune et al., 2002; McCune and Mefford, 1999).

MRPP is a non-parametric procedure used to test the hypothesis that no difference exists in composition between two or more groups of plots. As a distance measure between compositions of the plots we used the relative Sørensen distance, as it takes both composition (presence-absence of species) and abundance into account. A weighting option: $C_{I}=n_{I} / \sum n_{I}$ was used. It is the most widely used and recommend measure (Mielke, 1984). $C_{I}$ is the weight and is dependent on the number of items in a group, say $I$, and $n_{I}$ is the number of items in group $I$. We used 9999 permutations to statistically test if the within-group homogeneity is different from that expected by chance (random expectation). Both the MRPP and the indicator species analysis were calculated basing on prior identified vegetation cover classes for $\mathrm{T} 1, \mathrm{~T} 2$ and $\mathrm{T} 3$.

Species identified as indicator species mainly occur in one group (transect) and, occur in most of the plots in that group. We predict that if there is significant difference between the 1958 and 2004 data sets, the species identified as indicator species in the 1958 data set will be different from those identified in the 2004 data set. And if the transects are converging, there will be fewer indicator species in 2004 as compared to 1958 since there will be more species shared among the transects of 2004.

For the indicator species analysis, the output values of interest are the relative abundance (RA), relative frequency (RF), the highest indicator value (IV), a statistical significance of the indicator value $(P)$ and the cover class in which a particular species had the highest indicator value (Dufrêne and Legendre, 1997). RA is the concentration of each species in each cover type and is expressed as a proportion of a particular species in a particular class relative to its abundance in other classes. And RF is the faithfulness of occurrence of the species in that cover class and is expressed as the percentage of sample units in a class that contain that species. The statistical significance of the indicator value is evaluated using a Monte Carlo method where the sample units are randomly assigned to classes 1000 times. Each time, the highest indicator value is calculated. The probability of type 1 error $(P)$ is the proportion of times the randomized set's highest indicator value is equal or greater than the true indicator value of the data set (McCune et al., 2002).

We also explored changes in the abundance of large trees $(\mathrm{DBH} \geq 30 \mathrm{~cm})$ along $\mathrm{T} 1$. In 1958, large trees could mainly be found along T1. So, an independent table is presented for woody plants with $\mathrm{DBH} \geq$ $30 \mathrm{~cm}$ for only T1. Hence, to evaluate if there is still a good representation of the large trees along $\mathrm{T} 1$, the 2004 large trees were recorded against those identified in 1958 and the table was visually surveyed for differences.

\subsubsection{Distribution of woody individual $\geq 2 \mathrm{~cm}$ DBH in 2004}

To explore woody plants distribution at plot level, the positions of all individuals $\mathrm{DBH} \geq 2 \mathrm{~cm}$ at a single plot along each 2004 transect were analyzed using a spatial point pattern analysis. In presence of regular burning, woody individuals may occur in clusters either due to patchy fires or as an adaptation of the fire resistant species (Favier et al., 2004). The spatial point pattern analysis used here relates the observed set of coordinates to that obtained by a pattern of the same intensity but observed from a completely spatial random (CSR) distribution of individuals. The latter is based on the assumption that the number of individuals in an area $|A|$ of site $A$ follows a Poisson distribution with mean $\lambda|A|$ (Diggle, 2003).

The $K(h)$-function was chosen to model pattern in this study. It is estimated as

$\hat{K}(h)=A / N^{2} \sum_{i} \sum_{j} u_{i j}^{-1} I_{h}\left(h_{i j} \leq h\right), \quad i \neq j$

where $N$ is the number of individuals in $A, h_{i j}$ is the distance between the $i$ th and the $j$ th individuals and $I_{d}\left(h_{i j} \leq h\right)$ is an indicator function which is 1 if $h_{i j}$ is less than or equal to $d$ and 0 otherwise. When $i$ is the individual at a center of a circle passing through event 
$j, u_{i j}$ is the proportion of the circle that lies within $A$. To evaluate the significance of the distribution pattern displayed, i.e. if individuals occur in clusters or at regular intervals, simulation envelopes and averages of the plot were also calculated based on 999 simulations. The average of the simulation provides a reference line, and the maximum and minimum provide the 99\% simulation envelopes. If $\hat{K}(h)$ falls outside the simulation envelope, there is evidence against complete spatial randomness (CSR). $\hat{K}(h)$ also takes care of the edge effect making it an unbiased estimator of $K(h)$. The analysis was carried out using the spatial module of SPLUS (MathSoft, Inc.) software.

\section{Results}

With the three transects combined, in 1958 a total of 25 species belonging to 17 families were identified and in 2004, 36 species belonging to 22 families. The three most abundant species in 1958 were T. velutina, Lonchocarpus laxiflorus and Combretum binderanum and in 2004 they were C. molle, C. collinum and $C$. binderanum. Species that existed in 1958 but not encountered in 2004 were Afzelia Africana, Albizia coriaria, C. guenzii, Crataeva adansonii, Dombeya rotundifolia, Harrisonia abyssinica, Pseudocedrela kotschyi, Securinega virosa and Strychnos innoccua and the ones only occurring in the 2004 data set were $A$. grandibracteata, Caloncoba schweinfurthii, C. collinum, C. molle, D. mukole, Ficus sur, Grewia bicolor, Lannea barteri, L. schweinfurthii, Maytenus undata, Pappea capensis, Rothmannia urcelliformis, S. cocculoides, Syzigium sp., Teclea nobilis and Vitex doniana.

Considering the three size classes (trees, saplings and seedlings) along each transect, for the 2004 data, T3 had the lowest mean values and, the lowest and the highest standard deviation (Table 1), hence showing the largest variation. The median and the mean were almost equal for all groups at $\mathrm{T} 1$ and, for saplings and seedlings at T2 indicating a symmetric distribution for these groups. Overall, T2 had a higher mean number of species.

\subsection{Vegetation change}

Large changes over time occurred in the relative abundance of species found along each of the three
Table 1

Comparison of the 2004 number of species identified along the transects (T1, T2 and T3) located in the vicinity of Wairingo river in Murchison Falls National Park, Uganda

\begin{tabular}{lllrrr}
\hline $\begin{array}{l}\text { Transect } \\
\text { number }\end{array}$ & $\begin{array}{l}\text { Number } \\
\text { of plots }\end{array}$ & Groups & Range & Median & Mean \\
\hline T1 & 10 & Trees & $7-13$ & 10 & 10 \\
& & Saplings & $7-14$ & 12 & 11 \\
& & Seedlings & $7-14$ & 10 & 11 \\
& & Total & $14-16$ & 14 & 15 \\
T2 & \multirow{2}{*}{5} & Trees & $4-10$ & 8 & 7 \\
& & Saplings & $9-14$ & 11 & 11 \\
& & Seedlings & $8-15$ & 12 & 12 \\
& & Total & $14-17$ & 16 & 16 \\
T3 & \multirow{2}{*}{5} & Trees & $3-6$ & 3 & 4 \\
& & Saplings & $2-13$ & 5 & 6 \\
& & Seedlings & $4-13$ & 11 & 9 \\
& & Total & $12-15$ & 14 & 14 \\
\hline
\end{tabular}

transects. A comparison of species composition using the Sørensen similarity measure showed that in 2004, $\mathrm{T} 1$ and $\mathrm{T} 2$ had the highest compositional similarity ( $r=0.80$ ) (Fig. 3). In 1958, the highest compositional similarity was between $\mathrm{T} 2$ and T3 $(r=0.86)$. Comparison of the 2004 transects with their respective 1958 transects resulted in low coefficient values. The highest was between T3-2004 and T3-1958 $(r=0.62)$.

The trees with DBH $\geq 30 \mathrm{~cm}$ that existed along T1 in 1958 have all died off (Table 2). Only one large $T$. velutina $(\mathrm{DBH} 33.5 \mathrm{~cm})$ was encountered and two dead ones could also be identified as a T. velutina and a Stereospermum kunthianum. A few other dead ones were also encountered but they could not be identified because they had partly disintegrated. However, a new generation of trees $(10 \mathrm{~cm} \geq \mathrm{DBH}<25 \mathrm{~cm})$ with large numbers of $T$. velutina individuals now exists. A further check also revealed that T. velutina had very low abundance of seedlings $(\mathrm{DBH}<2 \mathrm{~cm}$ and height $\geq 50 \mathrm{~cm}$ ).

Axis 1 of the DCA explained $42 \%$ of the variation and axis 2 explained an additional $12.8 \%$. Along DCA axis 1 the 2004 transects are all far from the 1958 transects (Fig. 3). The major variation in the data is thus explained by time. In 1958, T1 was very different from T2 and T3 (as shown by the difference along axis 2) but has become very similar with the other transects in 2004 (Fig. 3). In 1958, transects T2 and T3 were very close and thus their composition was very similar. Transect T1 was different. In 2004, transects T1 and 
Table 2

Comparison of 1958 and 2004 trees composing the Terminalia woodland transect (T1) at Wairingo ranger post

\begin{tabular}{|c|c|c|c|c|c|c|c|c|c|}
\hline \multirow[t]{3}{*}{ Species } & \multirow[t]{3}{*}{ Plot no. } & \multicolumn{4}{|l|}{ Living } & \multicolumn{4}{|c|}{ Dead standing } \\
\hline & & \multicolumn{2}{|c|}{$\begin{array}{l}1958 \\
(\mathrm{DBH} \geq 30 \mathrm{~cm})\end{array}$} & \multicolumn{2}{|c|}{$\begin{array}{l}2004 \\
(\mathrm{DBH} \geq 30 \mathrm{~cm})\end{array}$} & \multicolumn{2}{|c|}{$\begin{array}{l}1958 \\
(\mathrm{DBH} \geq 30 \mathrm{~cm})\end{array}$} & \multicolumn{2}{|c|}{$\begin{array}{l}2004 \\
(\mathrm{DBH} \geq 30 \mathrm{~cm})\end{array}$} \\
\hline & & $\begin{array}{l}\text { No. of } \\
\text { trees }\end{array}$ & $\begin{array}{l}\text { Mean DBH } \\
(\mathrm{cm})\end{array}$ & $\begin{array}{l}\text { No. of } \\
\text { trees }\end{array}$ & $\begin{array}{l}\mathrm{DBH} \\
(\mathrm{cm})\end{array}$ & $\begin{array}{l}\text { No. of } \\
\text { trees }\end{array}$ & $\begin{array}{l}\mathrm{DBH} \\
(\mathrm{cm})\end{array}$ & $\begin{array}{l}\text { No. of } \\
\text { trees }\end{array}$ & $\begin{array}{l}\mathrm{DBH} \\
(\mathrm{cm})\end{array}$ \\
\hline Combretum gueinzii & 8 & 2 & $43(40-45)$ & & & & & & \\
\hline Ficus dicranostyla & 1 & 2 & $75(60-90)$ & & & & & & \\
\hline Ficus sp. & 7 & 1 & 90 & & & & & & \\
\hline Stereospermum kunthianuna & 7 & & & & & & & 1 & 43.9 \\
\hline \multirow[t]{10}{*}{ Terminalia velutina } & 1 & 2 & $40(30-50)$ & & & & & & \\
\hline & 2 & 5 & $35(30-55)$ & & & 2 & 25,25 & & \\
\hline & 3 & 5 & $35(30-45)$ & & & & & & \\
\hline & 4 & 2 & $55(45-50)$ & & & & & & \\
\hline & 5 & 5 & $40(30-50)$ & & & & & 1 & 40.2 \\
\hline & 6 & 3 & $50(35-65)$ & & & 1 & 35 & & \\
\hline & 7 & 6 & $45(35-50)$ & 1 & 33.5 & 2 & 25,70 & & \\
\hline & 8 & 9 & $40(30-45)$ & & & 1 & 35 & & \\
\hline & 9 & 6 & $45(35-65)$ & & & 2 & 10,25 & & \\
\hline & 10 & 5 & $45(40-50)$ & & & & & & \\
\hline
\end{tabular}

Plot no.: indicates the field plot at which the trees were identified. Woody plants of DBH $\geq 30$ were recorded in 1958 and the same size limit was used in 2004. They are referred to as large trees.

T2 are very close and both are further from T3. Changes in relative position among the transects between 1958 and 2004 show that both convergent and divergent processes are playing a role, as some transect combinations get closer while others get further apart. The location of the 2004 set of transects in the graph as compared to the 1958 transect, in that the transect sets are far apart, indicates that a shift in species composition of the whole set away from the 1958 species composition has occurred and all transects are moving in the same direction with respect to axis 1 .

In 1958, T1 and T2 had T. velutina as the most abundant species (with a relative abundance of $33.8 \%$ and $24.2 \%$, respectively). T1, additionally, had a high abundance of $H$. abyssinica $(10.4 \%)$ and Stereospemum kunthianum (18.5\%). T2 and T3 shared $C$. binderanum with a relative abundance of $21.8 \%$ and $11.9 \%$, respectively. T3 also had a high abundance of Carpolobia alba $(27.7 \%)$.

In 2004, T1 and T2 shared C. collinum and $C$. molle, which did not exist in 1958, as the most abundant species with $15.9 \%$ and $17 \%$, respectively for $\mathrm{T} 1$ and $14.3 \%$ and $15.2 \%$, respectively for $\mathrm{T} 2$. C. binderanum, which was more abundant along $\mathrm{T} 2$ and T3 in 1958, was most abundant along T1 in 2004.
Along T2, Gardenia jovis-tonantis and Hymenocardia acida were also highly abundant with $10.1 \%$ and $17.5 \%$, respectively. Along T3, Stereospermum kuntianum (20.9\%) was the most abundant species.

Morisita similarity index also separated well the 1958 transects from the 2004 transects (Fig. 4). Whereas the plots along each transect occured almost exclusively together in 1958, plots from the three transects were mixed in 2004 thus indicating compositional convergence of the plots in 2004.

\subsection{Species composition}

With MRPP, a significant difference in species composition between the transects was observed in both years with $A=0.29\left(P=2 \times 10^{-8}\right)$ for 1958 and $A=0.15\left(P=3.7 \times 10^{-6}\right)$ for 2004 . Considering the $P$ values for the 2 years, the 1958 transects were more dissimilar than the 2004.

The indicator species analysis revealed that although there was a higher number of species in 2004 (36) as compared to 25 in 1958, there were fewer indicator species identified in 2004 (Table $3 \mathrm{a}$ and b). In 1958, eight species had $P$-values lower than 0.01 as compared to 2 in 2004. In this study, $P$ is considered significant at 0.05 . Hence, in $1958 \mathrm{~T} 1 \mathrm{had} A$. coriaria 
Table 3

Indicator species analysis output for (a) 1958 and (b) 2004

\begin{tabular}{|c|c|c|c|c|c|c|c|c|c|}
\hline Species & RA-T1 & RF-T1 & RA-T2 & RF-T2 & RA-T3 & RF-T3 & IV & $P$ & Classes \\
\hline \multicolumn{10}{|l|}{ (a) 1958} \\
\hline Albizia coriaria & 79 & 80 & 21 & 20 & 0 & 0 & 63.4 & 0.013 & $\mathrm{~T} 1$ \\
\hline A. zygia & 5 & 30 & 60 & 100 & 35 & 60 & 60 & 0.021 & $\mathrm{~T} 2$ \\
\hline Bridelia schleroneuroides & 7 & 40 & 73 & 100 & 20 & 80 & 72.9 & 0.005 & $\mathrm{~T} 2$ \\
\hline C. binderanum & 1 & 20 & 78 & 100 & 21 & 100 & 77.7 & 0.004 & $\mathrm{~T} 2$ \\
\hline C. guenzii & 2 & 40 & 77 & 100 & 21 & 80 & 77.2 & 0.003 & $\mathrm{~T} 2$ \\
\hline Gardenia jovis-tonantis & 16 & 30 & 0 & 0 & 84 & 80 & 67.4 & 0.016 & $\mathrm{~T} 3$ \\
\hline Hymenocardia acida & 1 & 10 & 88 & 100 & 11 & 80 & 87.9 & 0.001 & $\mathrm{~T} 2$ \\
\hline Securidaca abyssinicus & 1 & 30 & 8 & 60 & 91 & 100 & 90.8 & 0.001 & $\mathrm{~T} 3$ \\
\hline Securidega virosa & 2 & 10 & 76 & 100 & 22 & 40 & 75.6 & 0.004 & $\mathrm{~T} 2$ \\
\hline Strychnos innocua & 8 & 60 & 81 & 100 & 11 & 40 & 80.6 & 0.001 & $\mathrm{~T} 2$ \\
\hline T. velutina & 28 & 100 & 65 & 100 & 6 & 80 & 65.5 & 0.001 & $\mathrm{~T} 2$ \\
\hline \multicolumn{10}{|l|}{ (b) 2004} \\
\hline A. grandibracteata & 85 & 80 & 7 & 60 & 7 & 20 & 68.4 & 0.018 & $\mathrm{~T} 1$ \\
\hline C. collinum & 55 & 100 & 45 & 100 & 0 & 0 & 54.7 & 0.036 & $\mathrm{~T} 1$ \\
\hline Dombeya mukole & 0 & 0 & 0 & 0 & 100 & 60 & 60 & 0.025 & $\mathrm{~T} 3$ \\
\hline Gardenia jovia-tonantis & 33 & 80 & 66 & 100 & 1 & 40 & 65.6 & 0.028 & $\mathrm{~T} 2$ \\
\hline Grewia bicolor & 60 & 100 & 36 & 100 & 4 & 80 & 59.7 & 0.021 & $\mathrm{~T} 1$ \\
\hline Hymenocardia acida & 27 & 90 & 72 & 100 & 1 & 20 & 71.6 & 0.007 & $\mathrm{~T} 2$ \\
\hline Maytenus undata & 0 & 0 & 4 & 20 & 96 & 80 & 76.6 & 0.002 & $\mathrm{~T} 3$ \\
\hline
\end{tabular}

The table indicates the concentration of each species along each transect (relative abundance: RA), the faithfulness of occurrence of the species along that transect (relative frequency: RF), the highest species indicator value across the transects (IV) the statistical significance of the indicator value $(P)$ and the transect along which the highest indicator value of the species occurred. T1: Terminalia woodland, T2: T. glaucescens conversion and T3: wooded grassland conversion. $P$ is significant at 0.05 .

as a significant indicator species, T2 had A. zygia, Bridelia schleroneuroides, C. binderanum, C. guenzii, Hymenocardia acida, Secirinega virosa, S. innocua and T. velutina and T3 had Gardenia jovis-tonantis and Securidega abyssinicus. In 2004, significant indicator species for T1 were A. grandbracteata, $C$. collinum and G. bicolor. For T2 they were Gardenia jovis-tonantis and Hymenocardia acida and, for T3 they were $D$. mukole and $M$. undata.

\subsection{Distribution of woody individuals $\geq 2 \mathrm{~cm}$} DBH in 2004

$\mathrm{T} 1_{\mathrm{p}}$ had the highest number of individuals (160) followed by $\mathrm{T} 2_{\mathrm{p}}(115)$ and $\mathrm{T} 3_{\mathrm{p}}$ had the lowest number of individuals (31). In the $\hat{K}(h)$ graphs (Fig. 2), if the data points (circles) fall directly over the central line, it indicates that the distribution is completely random. If, however, points fall above or below the central line, it indicates that there is recognizable clustering of individuals at the distance indicated, or, respectively, that a regular pattern of distribution is found. The $\hat{K}(h)$ graph for $\mathrm{T} 2 \mathrm{p}$ shows a highly significant departure from CSR. For distances less than $10 \mathrm{~m}, \mathrm{~T} 2$ p shows a clustered pattern and for distances between 10 and $20 \mathrm{~m}$, it shows a regular pattern of distribution (Fig. 2, $\mathrm{T} 2{ }_{\mathrm{p}}$ ). This indicates that individual woody plants occur together in clumps that are less than $10 \mathrm{~m}$ wide and these clumps are more or less spaced regularly at distances of 10-20 m from each other. $\mathrm{T} 1_{\mathrm{p}}$ and $\mathrm{T} 3_{\mathrm{p}}$ also show a departure from CSR at short distances but this is far less significant than for $\mathrm{T} 2_{\mathrm{p}}$. $\mathrm{T} 1_{\mathrm{p}}$ clusters are up to $8 \mathrm{~m}$ wide while $\mathrm{T} 3_{\mathrm{p}}$ clusters are up to $6 \mathrm{~m}$ wide (Fig. 2, $1_{1}$ and $\mathrm{T} 3_{\mathrm{p}}$ ).

\section{Discussion}

Although the species composition of the transects differs significantly in both 1958 and 2004, there is evidence that the transect vegetations have greatly changed, especially that of $\mathrm{T} 1$. The closeness in location of T1-2004 to the other 2004 transects on the ordination graph (Fig. 3), the higher compositional similarity, at plot level, between transects in 2004 as compared to the 1958 plots (Fig. 4) and the 

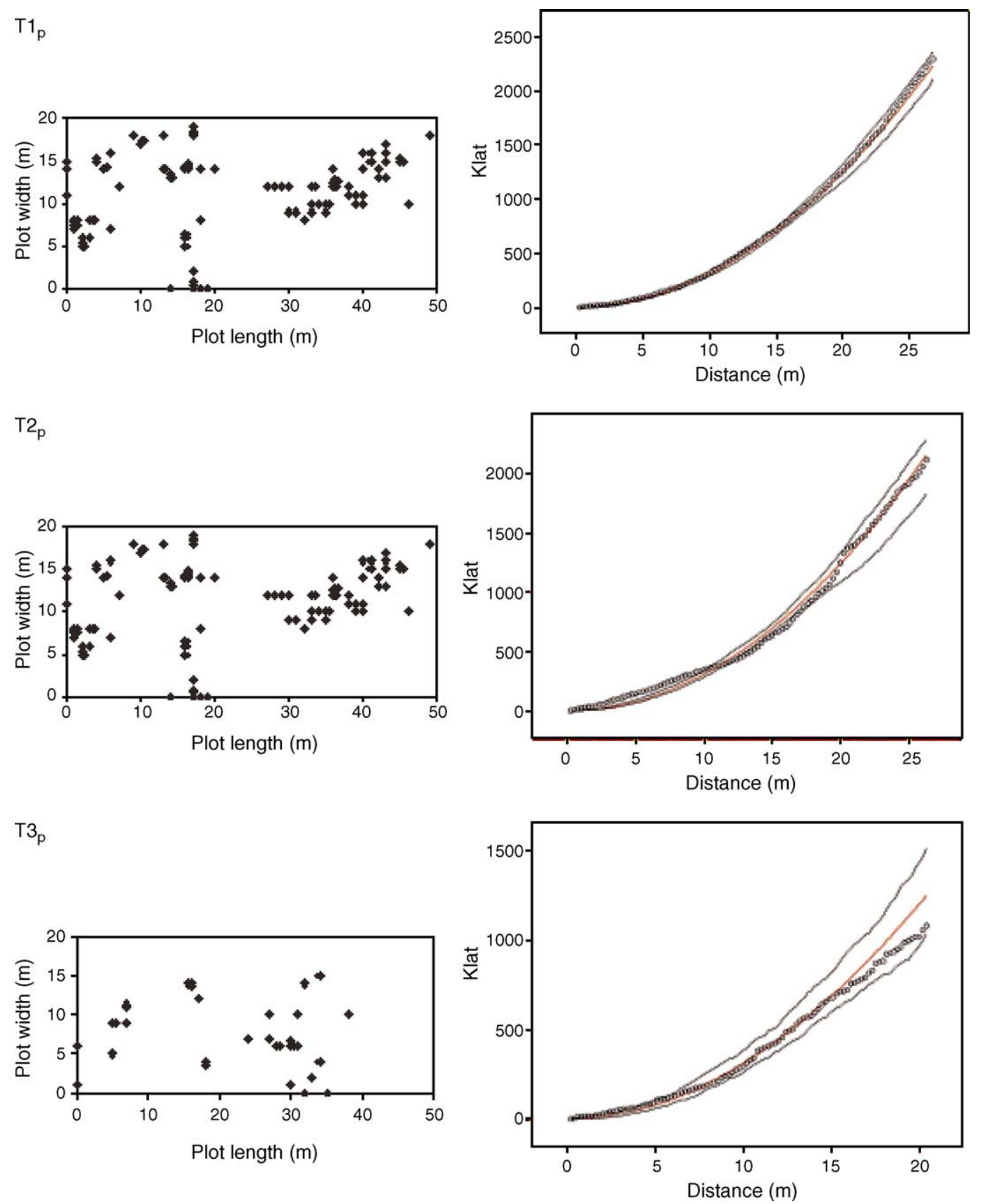

Fig. 2. Woody plants distribution of an individual plot along each transect (T1, T2 and T3) shown both as a scatter plot and a $K$-function with the $99 \%$ confidence envelopes.

identification of fewer indicator species in 2004 as compared to 1958 (Table $3 \mathrm{a}$ and $\mathrm{b}$ ) are all indicators of convergence of the vegetation types represented by the transects. The compositional shift in location of all
2004 transects along DCA axis 1, away from the 1958 transects, and their being compositionally close (Fig. 3) is an indicator that the vegetation is adjusting to suit the existing fire regime (van Wilgen et al., 1998) 


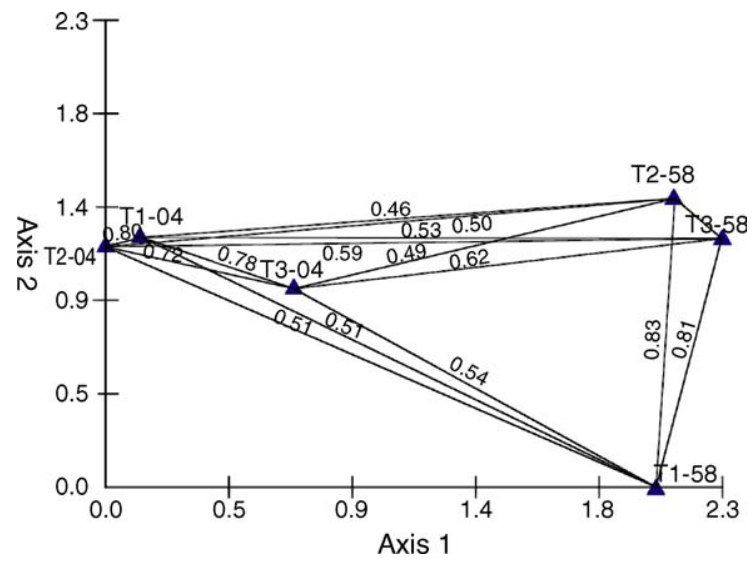

Fig. 3. DCA graph indicating relationship between the transect in terms of their species composition and Sørensen similarity index. T1-1958, T2-1958 and T3-1958 are the three transects in 1958 and, T1-2004, T2-2004 and T3-2004 are the respective transects in 2004.

and as a result the area may become more homogeneous. If the current fire regime is maintained into the future, a homogeneous vegetation type that is compositionally different from any of the 1958 transects may emerge. To maintain the varied landscape, a variation in burning frequency is needed with a reduction of fire in some vegetation types (Skowno et al., 1999) especially the Terminalia woodland (Spence and Angus, 1971).

T. velutina had the highest relative abundance along T1 and T2 in 1958 but in 2004, C. collinum and $C$. molle, which are more adapted to frequent disturbance, had become most abundant. Taking tree size (DBH) as a proxy for age (Wells and Getis, 1999), we argue that most of the Terminalia trees on T1 regenerated around the same time since most of them occur within a narrow DBH range ( $\geq 10 \mathrm{~cm} \mathrm{DBH}<25 \mathrm{~cm}$, data details not shown). The 1958 large Terminalia trees supplied seed, which resulted into the current individuals with DBH $\geq 10 \mathrm{~cm}$, and as the large trees died off, there were hardly any mature trees to produce new seed and thus the lower T. velutina relative abundance in 2004 . The death of the parent trees, however, opened up the canopy and also left behind a nutrient rich environment (Ludwig et al., 2004) which enabled the regenerated plants to thrive.

The species composition similarity values between the respective (1958 and 2004) transects (Fig. 3) and the disappearance of almost all the large trees along T1 (Table 3) are evidence of the changes that have taken place. Elephants may have played a role in the reduction of the large trees (Buechner and Dawkins, 1961) but there was evidence of elephant disturbance tolerance (Sheil and Salim, 2004) on some of the dead large trees encountered (e.g. Fig. 5a). Although the tree was highly scarred, it grew back to cover the damaged areas. Such trees probably died later when they could no longer withstand the impact of the fires. Many of the living individuals also had old scars that were the result of previous elephant gouging. Within plot 5 along T1, there were as many as five dead trees DBH $>30 \mathrm{~cm}$ and several others in its vicinity. Unfortunately, most of them could not be identified. These were most likely not killed during the time when elephants were abundant (in the 1960s) but must have died recently. Hence, we conclude that the fire regime that has remained unchanged for such a long time has contributed to the loss of the large trees that did survive destruction by elephants. This is in line with the findings of Ben-Shahar (1998) who indicates that fire precipitates the decline of mature trees in woodlands.

Whereas high numbers of herbivores, especially elephants, have been associated with destruction of woody vegetation (Laws, 1970; Lewis, 1986), their elimination often leads to increase in vegetation cover but with lower diversity of both grasses and woody species (Smart et al., 1985). Increase in grass cover in turn leads to more intense fires (Huston, 1994; Salvatori et al., 2001) and since burning has gone on for a long time, the areas have started to respond to the disturbance in a similar fashion (Shackleton et al., 1994).

Analysis of distribution patterns revealed clustering of individuals, which has often been identified as a fire survival mechanism (Favier et al., 2004). The pattern displayed by the $\mathrm{T} 2$ p plot (Fig. 2) is probably an indicator of a survival mechanism of some of the dominant species, Gardenia jovis-tonantis and Hymenocardia acida, which were often encountered in clusters. Elsewhere, other species, e.g. Pinus torreyana have been observed to display similar patterns in presence of regular burning (Wells and Getis, 1999). The clustering reduces fire penetration by reducing grass cover within the cluster and the young trees also protect the parent tree from subsequent fires (Favier 


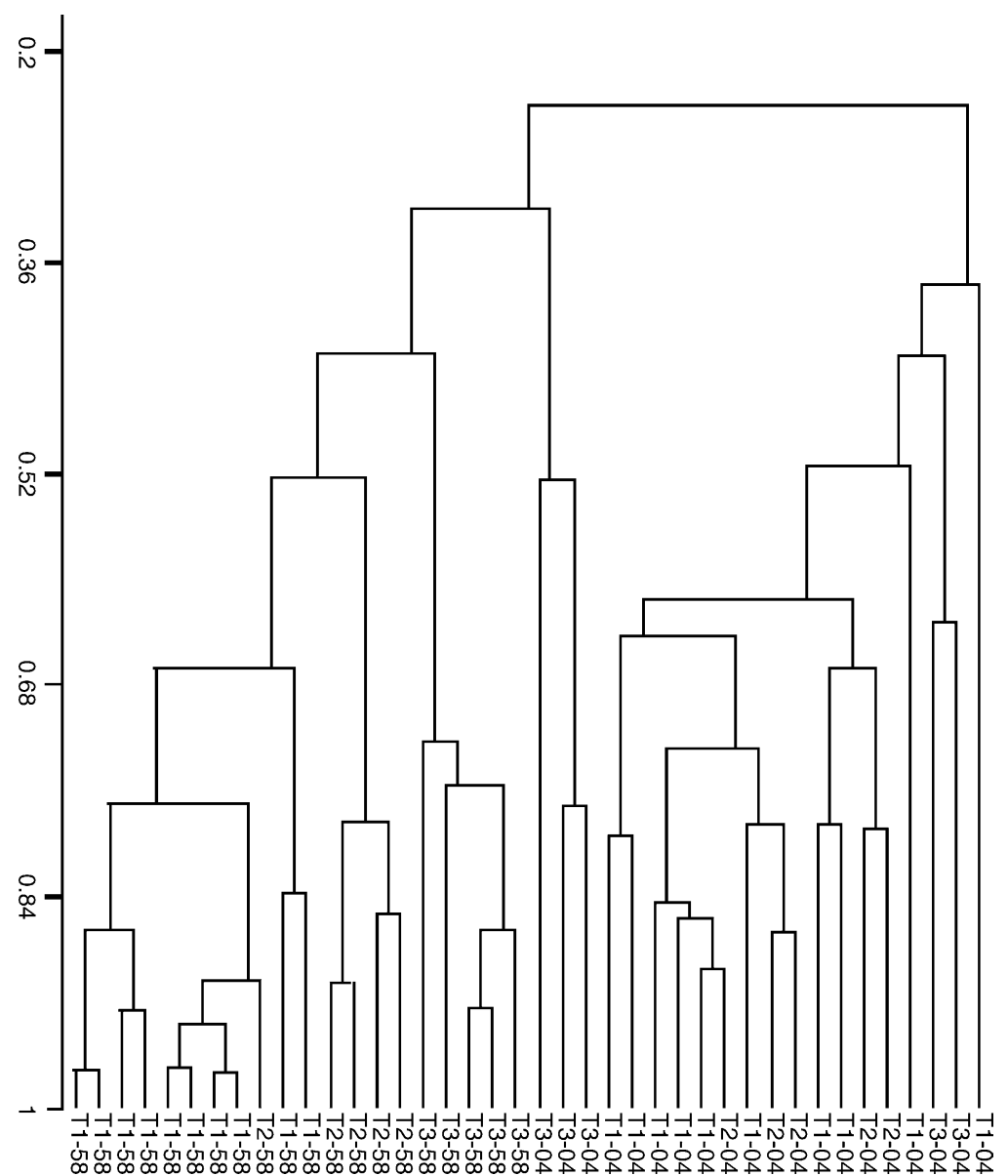

Fig. 4. A dendrogram indicating species composition similarity between plots along both the 1958 and the 2004 transects analyzed using Morisita similarity index. T1-1958, T2-1958 and T3-1958 are the three transects in 1958 and, T1-2004, T2-2004 and T3-2004 are the respective transects in 2004.

et al., 2004; Witkowski and Garner, 2000). The clustering developed in these species also ensures survival of most seedlings which often occur below the parent plant (Acharya, 1999; Wilson and Witkowski, 2003) where the fuel load is often lower due to the shade of the crowns of the parent trees (Gautier and Spichiger, 2004). Although the distribution pattern was more evident in $\mathrm{T} 2 \mathrm{p}$, all three transects displayed some level of clustering (Fig. 2). We suggest that woody plants in these vegetation types have developed clustering as a survival mechanism against the existing fire disturbance regime.

The park authorities aim at creating a landscape with diverse habitats (Spence and Angus, 1971; Wheater, 1971) and variation of fire use has been recommended for this purpose (Uganda Wildlife Authority, 2001). However, efforts made over the years to vary the fire regimes in the park (Wheater, 1971) have had little success because of the increase in human settlement in the vicinity of the park and the low financial and human resource to implement the plans. The annual fires have in turn destroyed almost all the big trees. And since these are the main seed source, the consequence has been a reduction in the abundance of some of the species, especially $T$. velutina in the regeneration (DBH $<2 \mathrm{~cm}$ ). Increase in grass cover due to fewer grazers and death of the large woody plants also fostered the occurrence of hotter fires which in turn favored more fire adapted woody species. An example is the replacement of T. velutina 


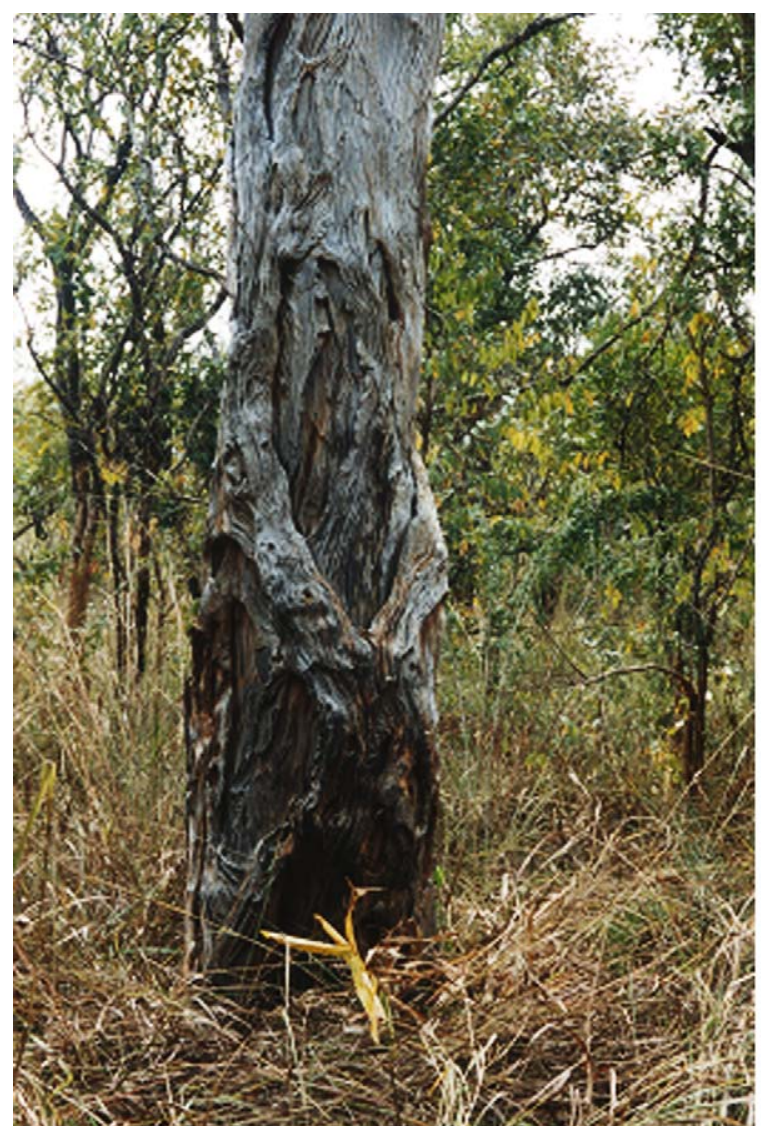

(a)

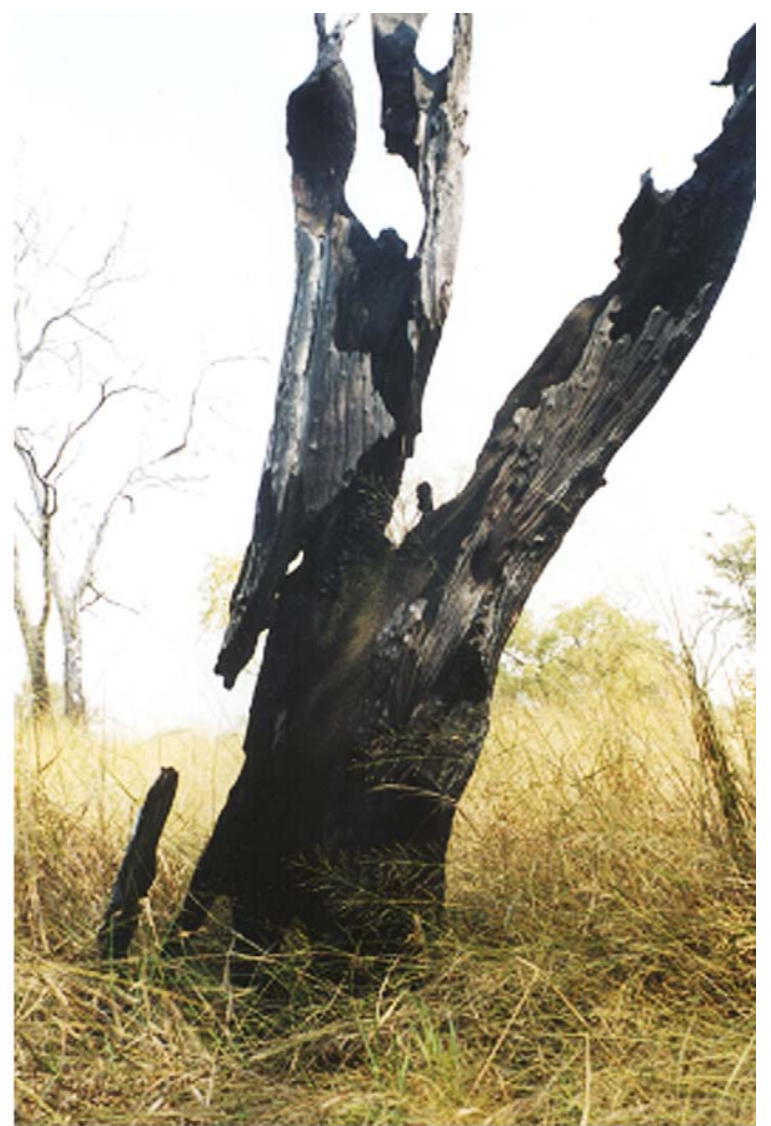

(b)

Fig. 5. Photographs of some of the dead trees with DBH $>30 \mathrm{~cm}$ encountered along T1. The pattern in (a) shows parts that had been gauged by elephants but had eventually recovered and the tree continued growing. The constant fires have slowly eaten away on the tree in (b). Two other trees, in the background, were also dead.

along $\mathrm{T} 1$ and $\mathrm{T} 2$, as the most abundant species, by Combretum species.

All sampled areas in this study have changed in woody plants cover and composition, and there is ample evidence that the vegetations are converging. To counterbalance this unifying effect, and since one of the aims of the park is to create a diverse habitat, fire regimes need to be varied over the area. For T1 vegetation, early burning with an interval of 3-5 years should be carried out. This will allow for the regeneration of the Terminalia species and the occasional burning will eliminate forest species. In the $\mathrm{T} 2$ vegetation, late burning but with a longer interval (3-5 years) should be practiced while in the T3 vegetation, late burning with an interval of at least 2 years should be practiced. Areas with similar vegetation should be identified so that they are burnt in a rotational way to ensure availability of forage for the animals.

Woodland decline, as occurred in Murchison Falls National Park, was observed in many parks and reserves in East, South and Central Africa (Brooks and Buss, 1962; Guy, 1981; Lamprey et al., 1967; Parker, 1983; Savidge, 1968; Van Wyk and Fairall, 1969). Much of the change was attributed to the high numbers of herbivores, especially elephants, and increased use of fire (Dublin and Douglas-Hamilton, 1987; Dublin et al., 1990). Although the herbivore numbers were reduced through hunting and disease, e.g. rinderpest, the fire regimes have hardly changed. In such areas, the fire regime variation suggested in this study needs to be implemented in order to restore the woody plant 
cover and composition. At the same time, more focused studies for the specific parks and reserves need to be carried out so as to fine-tune the fire regimes to those fully applicable to each reserve area, given variation in environmental variables, e.g. rainfall and soil characteristics.

For future management support, permanent plots for vegetation monitoring in the park need to be (re)established and maintained. Thresholds of vegetation change need to be set which, if reached, should trigger an assessment of the causes of the change and which should lead to possible corrective actions. Additional data sets from other parts of the conservation area, e.g. Pandera woodlands, Rabongo forest and the banks of River Nile ought to be analyzed and interpreted to substantiate the observed trend.

\section{Acknowledgements}

We thank the UWA field staff for their support during the data collection period. We thank also Mr. Dumba for being there for us to sort out the species identification problems and for all the logistical support he provided during the data collection period. We express our gratitude to Professor Dr. Alfred De Gier for his continued support and for his valuable comments during the preparation of this manuscript.

\section{References}

Acharya, B., 1999. Forest biodiversity assessment: a spatial analysis of tree species diversity in Nepal. PhD Thesis. Leiden University, Enschede, 199 pp.

Barnes, R.F.W., 1983. The elephant problem in Ruaha National Park, Tanzania. Biol. Conserv. 26, 127-148.

Ben-Shahar, R., 1993. Patterns of elephant damage to vegetation in northern Botswana. Biol. Conserv. 65, 249-256.

Ben-Shahar, R., 1998. Changes in structure of savanna woodlands in northern Botswana following the impacts of elephants and fire. Plant Ecol. 136, 189-194.

Brooks, A.C., Buss, I.O., 1962. Past and present status of elephant in Uganda. J. Wildl. Manage. 26, 38-50.

Buechner, H.K., Dawkins, H.C., 1961. Vegetation change induced by elephants and fire in the Murchison Falls National Park, Uganda. J. Ecol. 42 (4), 752-766.

Chandler, C., Cheney, P., Thomas, P., Trabaud, L., Williams, D., 1983. Forest fire behavior and effects. In: Fire in Forestry, Wiley, New York, p. 357.
Diggle, P.J., 2003. Statistical Analysis of Spatial Point Patterns. Arnold, Hodder Headline Group, New York.

Dublin, H.T., Douglas-Hamilton, I., 1987. Status and trends of elephants in the Serengeti-Mara ecosystem. Afr. J.Ecol.25, 19-33.

Dublin, H.T., Sinclair, A.R.E., McGlade, J., 1990. Elephants and fire as causes of multiple stable states in the Serengeti-Mara woodlands. J. Anim. Ecol. 59, 1147-1164.

Dufrêne, M., Legendre, P., 1997. Species assemblages and indicator species: the need for a flexible asymmetrical approach. Ecol. Monogr. 67 (3), 345-366.

Eckhardt, H.C., van Wilgen, B.W., Biggs, H.C., 2000. Trends in woody vegetation cover in Kruger National Park, South Africa, between 1940 and 1998. Afr. J. Ecol. 38, 108-115.

Eggeling, W.J., Dale, R.I. (Eds.), 1952. The Indigenous Trees of the Uganda Protectorate. Uganda Government Printer, Entebbe.

Favier, C., Chave, J., AFabing, A., Schwartz, D., Dubois, M.A., 2004. Modelling forest-savanna mosaic dynamics in man-influenced environments: effects of fire, climate and soil heterogeneity. Ecol. Model. 171, 85-102.

Gautier, L., Spichiger, R., 2004. The forest-savanna transition in West Africa. In: Poorter, L., Bongers, F., Kouamé, F.N., Hawthorne, W.D. (Eds.), Biodiversity of West African Forests: An Ecological Atlas of Woody Plant Species. CAB International, Wallingford, pp. 33-40.

Guy, P.R., 1981. Changes in biomass and productivity of woodlands in Sengwa Research Area, Zimbabwe. J. Appl. Ecol. 18, 507519.

Hamilton, A., 1991. A Field Guide to Ugandan Forest Trees. Makerere University, Kampala.

Hatton, J.C., Smart, N.O.E., 1984. The effect of long-term exclusion of large herbivores on soil nutrient status in Murchison Falls National Park, Uganda. Afr. J. Ecol. 22, 23-30.

Huston, M.A., 1994. Biological Diversity: The Coexistence of Species on Changing Landscapes. Cambridge University Press, London.

Janson, s., Vegelius, J., 1981. Measures of ecological association. Oecologia 49, 371-376.

Kennard, D.K., Gould, K., Putz, F.E., Fredericksen, T.S., Morales, F., 2002. Effect of disturbance intensity on regeneration mechanisms in a tropical dry forest. For. Ecol. Manage. 162, 197-208.

Lamprey, H.F., Glover, P.E., Turner, M.I.M., Bell, R.H.V., 1967. The invasion of the Serengeti National Park by elephants. East Afr. Wildl. J. 5, 151-166.

Laws, R.M., 1970. Elephants as agents of habitat and landscape change in East Africa. Oikos 21, 1-15.

Laws, R.M., Parker, I.S.C., Johnstone, R.C.B., 1975. Elephants and their Habitants. The Ecology of Elephants in North Bunyoro, Uganda. Oxford University Press, London.

Leps, J., et al., 2001. Seperating the chance effect from other diversity effects in the functioning of plant communities. Oikos 92, 123-134.

Leuthold, W., 1977. Changes in tree populations in Tsavo National Park, Kenya. East Afr. Wildl. J. 15, 61-69.

Leuthold, W., 1996. Recovery of woody vegetation in Tsavo National Park, Kenya, 1970-1994. Afr. J. Ecol. 34, 101112. 
Lewis, D.M., 1986. Disturbance effects on elephant feeding: evidence of compression in Luangwa Valley, Zambia. Afr. J. Ecol. 24, 227-241.

Lock, J.M., 1977. Preliminary results from fire and elephant exclusion plots in Kabalega National Park, Uganda. East Afr. Wildl. J. $15,229-232$.

Ludwig, F., de Kroon, H., Berendse, F., Prins, H.H.T., 2004. The influence of savanna trees on nutrient, water and light availability and the understorey vegetation. Plant Ecol. 170, 93-105.

McCune, B., Grace, J.B., Urban, D.L., 2002. Analysis of the Ecological Communities. MjM Software, Gleneden Beach, OR, USA.

McCune, B., Mefford, M.J., 1999. Multivariate Analysis of Ecological Data, Version 4.25. MjM Software, Gleneden Beach, OR, USA.

McGuffog, T., Dyer, R., Williams, B., 2001. Burning operations. In: Dyer, R., Jacklyn, P., Partridge, I., Russell-Smith, J., Williams, D. (Eds.), Savanna Burning: Understanding and Using Fire in Northern Australia. Tropical Savannas CRC, Darwin, pp. 82101.

McShane, T.O., 1987. Elephant-fire relationship in Combretum/ Terminalia woodland in south-west Niger. Afr. J. Ecol. 25, 79-94.

Mielke, P.W.J., 1984. Meteorogical applications of permutation techniques based on distance functions. In: Krishnaiah, P.R., Sen, P.K. (Eds.), Handbook of Statistics. Elsevier Science Publishers, pp. 813-830.

Parker, I.S.C., 1983. The Tsavo story: an ecological case history. In: Owen-Smith, R.N. (Ed.), Management of Large Mammals in African Conservation Areas. Haum Educational Publishers, Pretoria, pp. 37-49.

Pickett, S.T.A., White, P.S., 1985. The Ecology of Natural Disturbance and Patch Dynamics. Academic Press, San Diego.

Sabiti, E.N., Wein, R.W., 1988. Fire behavior and invasion of Acacia sieberiana into savanna grassland openings. Afr. J. Ecol. 26, 301-313.

Sagar, R., Raghubanshi, A.S., Singh, J.S., 2003. Tree species composition, dispersion and diversity along a disturbance gradient in a dry tropical forest region of India. For. Ecol. Manage. 186, 61-71.

Salvatori, V., Egunyu, F., Skidmore, A.K., de Leeuw, J., van Gils, H.A.M., 2001. The effects of fire and grazing pressure on vegetation cover and small mammal population in the Masai Mare National Reserve. Afr. J. Ecol. 39, 200-204.

Savidge, J.M., 1968. Elephants in Ruaha National Park, Tanzania: management problem. East Afr. Agric. Forest. J. 33, 191-196.

Shackleton, C.M., Griffin, N.J., Banks, D.I., Mavrandonis, J.M., Shackleton, S.E., 1994. Community structure and species composition along a disturbance gradient in a communally managed South African savanna. Vegetatio 115, 157-167.
Sheil, D., Salim, A., 2004. Forest tree persistence, elephants and stem scars. Biotropica 35 (4), 505-521.

Skowno, A.L., Midgley, J.J., Bond, W.J., Balfour, D., 1999. Secondary succession in Acacia nalotica (L.) savanna in the Hluhluwe Game Reserve, South Africa. Plant Ecol. 145, 1-9.

Smart, N.O.E., Hatton, J.C., Spence, D.H.N., 1985. The effect of long-term exclusion of large herbivores on vegetation in Murchison Falls National Park, Uganda. Biol. Conserv. 33, 229-245.

Spence, D.H.N., Angus, A., 1971. African grassland managementburning and grazing in Murchison Falls National Park, Uganda. In: Duffey, E., Watt, A.S. (Eds.), The Scientific Management of Animal and Plant Communities for Conservation. Blackwell, London.

Tafangenyasha, C., 2001. Decline of the mountain acasia, Brachystegia glauscens in Gonarezhou National Park, southeast Zimbabwe. J. Environ. Manage. 63, 37-50.

Trollope, W.S.W., 1993. Fire regime of the Kruger National Park for the period 1980-1992. Koedoe 36, 45-52.

Uganda Wildlife Authority, 2001. Murchison Falls National Park, Bugungu Wildlife Reserve, Karuma Wildlife Reserve: General Management Plan 2001-2011. Printers Den, Kampala.

van Langevelde, F., et al., 2003. Effects of fire and herbivory on the stability of savanna ecosystems. Ecology 84 (2), 337-350.

Van Wijngaarden, W., 1985. Elephants-trees-grass-grazers; relationships between climate, soil, vegetation and large herbivores in a semi-arid savanna ecosystem (Tsavo, Kenya). PhD Thesis. Agriculture University, Wageningen, Enschede, 159 pp.

van Wilgen, B.W., Biggs, H.C., Potgieter, A.L.F., 1998. Fire management and research in the Kruger National Park, with suggestion on the detection of thresholds of potential concern. Koedoe 41, 69-87.

Van Wyk, P., Fairall, N., 1969. The influence of the African elephant on the vegetation of Kruger National Park. Koedoe 12, 57-89.

Wells, M.L., Getis, A., 1999. The spatial characteristics of stand structure in Pinus terreyana. Plant Ecol. 143, 153-170.

Western, D., Maitumo, D., 2004. Woodland loss and restoration in a savanna park: a 20-year experiment. Afr. J. Ecol. 42, 111-121.

Wheater, R.J., 1971. Problems of controlling fires in Uganda National Parks. In: Proceedings of the Annual Tall Timbers Fire Ecology Conference.

Wilson, B.G., Witkowski, E.T.F., 2003. Seed banks, bark thickness and change in age and size structure (1978-1999) of the African savanna tree, Burkea africana. Plant Ecol. 167, 151-162.

Witkowski, E.T.F., Garner, R.D., 2000. Spatial distribution of soil seed banks of three African savanna woody species at two contrasting sites. Plant Ecol. 149, 91-106.

Wolda, H., 1983. Diversity, diversity indices and tropical cockroaches. Oecologia 58, 290-298.

Yeaton, R.I., 1988. Porcupines, fires and the dynamics of the tree layer of the Burkea africana savanna. J. Ecol. 76, 1017-1029. 